\title{
OPERATIVNA REVIZIJA - ALAT I KOREKTOR MENADŽMENTA
}

\section{OPERATIVE AUDIT - TOOL OF MANAGEMENT AND MANAGEMENT CORRECTOR}

\section{Nevenka Nićin}

Fakultet za poslovno industrijski menadžment, Kneza Višeslava 27, Beograd, Republika Srbija

\section{Milija Bogavac}

Fakultet za poslovno industrijski menadžment, Kneza Višeslava 27, Beograd, Republika Srbija

\section{(C) MESTE NGO}

\section{Sažetak:}

Operativna revizija prati celokupno ostvarenje ciljeva, efektivnost poslovnih postupaka i interne kontrole, rezultate menadžera i druge nefinansijske aspekte poslovanja, koristeći logičke revizijske tehnike; privođenje svrsi organizacionih ciljeva, operacija, kontrolnih procesa, komunikacije $i$ informacionih sistema. Smanjenje potencijalnih rizika, odnosno, stepena izloženosti gubicima usled nastanka neizvesnih nepovoljnih događaja, u direktnoj je srazmeri sa nedovoljnim obimom kontrole, nedostatkom informacija i vremena za donošenje optimalnih odluka.

\section{Ključne reči:}

sistem interne kontrole, operativna revizija, bonitet, rizici, informacioni sistemi

\begin{abstract}
:
Operative audit follows the overall achievement of every goal, effectiveness of business actions and internal control, manager results and other non-financial aspects of business, by the use of logical audit techniques. It also follows purposeful organizations' goals, their operations, control processes of communication and knowledge information systems. Reduction of potential risks and exposure to the losses in creation of unreliable and unwelcome events is in direct proportion with insufficient control, lack of information, and time in which those optimal decisions are made.
\end{abstract}

Adresa autora zaduženog za korespodenciju: Nevenka Nićin

麦”= nicinnevenka@gmail.com

\section{Keywwords:}

internal control system, operative audit, reliability of enterprise, risk, information systems 


\section{Uvod}

Operativna revizija prati celokupno ostvarenje ciljeva, efektivnost poslovnih postupaka i interne kontrole, rezultate pojedinih menadžera i druge finansijske aspekte poslovanja. Koristi logičke revizijske tehnike da privede svrsi organizacione ciljeve, operacije, kontrolne procese, komunikaciju i informacioni sistem. (Mandić, 2001) Primena nove tehnologije operativne revizije, nepoznate u našoj praksi, realizovane kroz periodično praćenje funkcionisanja sistema internih kontrola i permanentnu ocenu boniteta preduzeća će menadžmentu staviti na raspolaganje moćan instrument za upravljanje.(Weihrich \& Koontz, 1994)

Prevare menadžmenta odnose se na namerno pogrešnu interpretaciju top menadžmenta (kod nas često vrhovnog menadžera), prema osobama izvan poslovne organizacije preduzeća. Često se ove prevare čine izdavanjem falsifikovanih finansijskih izveštaja, čija je svrha da navedu na pogrešna razmišljanja, vlasnike preduzeća, osnivače, poverioce $\mathrm{i}$ javnost. Razlozi su najčešće lična materijalna korist, lični psihološki razlozi vezani za zadržavanje osećaja moći, politički uticaji, kao i stvaranje podaničkog mentaliteta poslovanja zahvaljujući strahovanju i pogrešnom interpretiranju odnosa vlasnika i menadžera. Još jedan oblik prevare koju može da napravi menadžment jeste pogrešna upotreba sredstava preduzeća.

Poznavanje organizacije, organizovanja, menadžmenta, strukture organizacije, raspona upravljanja, merenja uspešnosti pojedinih segmenata (profitni centri, troškovni centri), upravljačkog računovodstva i sistema računovodstva po mestu odgovornosti; podela na organizacione jedinice, ovlašćenja u organizaciji, moć, delegiranje ovlašćenja, organizaciona kultura, lične crte menadžera, obrazovanje menadžera, promene i konflikti, motivacija u organizaciji, deo su tema čije razmatranje daje početne pretpostavke za razumevanje sistema internih kontrola i operativne revizije.

Operativna revizija ima za cilj da ponovo potvrdi menadžmentu da je interna kontrola čvrsta, da uoči neslaganja i nedostatke u procesima, te da preporuči poboljšanja, i naravno ubedi menadžment da prihvati i uspešno primeni preporuke revizije za poboljšanje. (Andrić, 1999)

\section{Računovodstveni sistem}

$U$ modernom poslovnom svetu poznavanje računovodstva ne samo da je korisno - već je to istovremeno i veština da se preživi. Ono je način na koji poslovni ljudi definišu ciljeve, mere ostvarene rezultate i procenjuju ostvarene učinke.

Računovodstvo je sredstvo pomoću koga merimo i opisujemo rezultate ekonomske aktivnosti . Svaki investitor, menadžer, odnosno donosilac poslovnih odluka mora dobro da poznaje računovodstvene termine i koncepte ukoliko želi da učestvuje i aktivno komunicira sa ostalim poslovnim subjektima u okruženju. Računovodstvo je podjednako važno za uspešan rad vlade, ostvarenje socijalnih programa, ili za rad crkve, kao što je to slučaj i sa poslovnim organizacijama.

Osnovna svrha računovodstva je da donosiocima odluka obezbedi informacije korisne za donošenje vitalnih ekonomskih odluka. Kao ulaz u računovodstveni proces javlja se ekonomska aktivnost odnosno poslovne transakcije, a kao izlaz ili rezultat te aktivnosti se javljaju korisne informacije. Primarni cilj računovodstva sastoji se u tome da se u potpunosti razume priroda računovodstvenih informacija i razvije sposobnost da se one efikasno koriste.Menadžmentu stoje na raspolaganju sve računovodstvene informacije koje postoje u okviru pojedinih ekonomskih entiteta, a većina tih informacija se distribuira investitorima, kreditorima, finansijskim analitičarima, sindikatima, najširoj javnosti, pa čak i konkurentskim firmama. (Milojević, 2010)

Korisnicima informacija izvan poslovnih entiteta se dostavljaju tzv. finansijske informacije opšte namene u formi kompleta računovodstvenih izveštaja koji se obično nazivaju finansijskim izveštajima, a pripremaju se u skladu sa opšteprihvaćenim računovodstvenim principima.

Komplet finansijskih izveštaja uključuje:

- bilans stanja, koji pokazuje finansijsku poziciju na određeni dan;

- bilans uspeha ili račun dobitka i gubitka, koji prikazuje profitabilnost biznisa u periodu za koji je taj bilans sastavljen;

- bilans sopstvenog kapitala, koji objašnjava promene do kojih je došlo u visini sopstvenog kapitala; i

- bilans tokova gotovine, koji prikazuje priliv i odliv gotovine $u$ istom periodu za koji je sastavljen i 
bilans uspeha kao i napomene uz finansijske izveštaje.

Odluke menadžmenta su bazirane na informacijama koje potiču iz računovodstvenog sistema. Menadžeri imaju potrebu da se uvere da su računovodstvene informacije koje im se dostavljaju tačne i pouzdane. Takvo uverenje se obezbeđuje uz pomoć sistema interne računovodstvene kontrole $u$ okviru kompanije. Taj sistem podrazumeva sve mere koje organizacija koristi da se zaštiti od grešaka, pronevera, i sl.; za obezbeđenje pouzdanosti računovodstvenih podataka; kao i za obezbeđenje usaglašene primene poslovne politike koje je menadžment ranije definisao.

Sigurnost korisnicima van organizacije o tome da li finansijski izveštaji koje prezentira menadžment pružaju potpunu i pouzdanu sliku o finansijskoj poziciji i poslovnim rezultatima organizacije se obezbeđuje putem revizije finansijskih izveštaja kompanija, koje obavljaju firme u kojima su angažovani ovlašćene javne računovođe (revizori). Revizori su eksperti na području finansijskog izveštavanja koji su potpuno nezavisni od kompanije koja prezentira finansijske izveštaje. (Milojević, 2010) Revizorske firme izražavaju svoje profesionalno mišljenje o tome da li su finansijski izveštaji koji se dostavljaju subjektima izvan kompanije objektivni i istiniti ili nisu.

Finansijski sistem, odnosno računovodstvo kao njegov podsistem su bitne komponente modernog biznisa i osnovne pretpostavke za dalji progres jer obezbeđuje pouzdane obračune i bilanse poslovanja, koji su transparentni i uporedivi i kao takvi neophodni investitorima, zadovoljava interne potrebe preduzeća kada je reč o troškovima poslovanja i ceni koštanja njihovih proizvoda i usluga; pomaže ubrzanju privrednog razvoja, bilo od strane bankarskog sektora, specijalizovanih agencija za razvoj ili međunarodnih institucija.

Pritisci i zahtevi globalizovanog tržišta i opšta primena međunarodnih računovodstvenih standarda imaju višestruke poslovne efekte koji se efektuiraju kroz smanjenje troškova poslovanja multinacionalnih kompanija, harmonizaciju internog i eksternog finansijskog izveštavanja bez obzira na to u kojoj se zemlji to poslovanje odvija; pospešenje investiranja van nacionalnih granica i otuda poboljšanje alokacije štednje koja je namenjena investicijama; smanjenje rizika; omogućavanje računovodstvenim ekspertima da efikasno obavljaju svoju funkciju širom sveta. (Pušara, 2004)

Investitori se opredeljuju za ona tržišta koja su usvojila i primenjuju međunarodno priznate računovodstvene standarde za finansijsko izveštavanje, a znatno manje poverenje $u$ one zemlje koje primenjuju nacionalne računovodstvene standarde. Ovo iz razloga što obezbeđenje informacija u skladu sa poznatim setom računovodstvenih standarda koji su kvalitetni, transparentni i uporedivi znatno smanjuje rizik investiranja i snižava troškove pribavljanja kapitala. Primarna i vitalna svrha računovodstva je da donosiocima odluka pomogne $u$ izboru između alternativnih tokova akcija.

Finansijsko izveštavanje, pored niza relevantnih faktora, mora u svom fokusu primarnih ciljeva da ima u vidu obezbeđenje što višeg nivoa opšteg društvenog blagostanja, kao vrhovnog cilja svakog društva.

Komponente finansijskog izveštavanja su: finansijski izveštaji, finansijske informacije, korisne informacije, optimalne poslovne odluke, efikasna tržišta kapitala, dovoljni izvori kapitala, zdrava ekonomija, i društveno blagostanje.

Korisnost informacija obezbeđuje se onda kada su i ako su iste relevantne, tačne, blagovremene, ažurne, uporedive i razumljive. Da bi informacije bile istovremeno i korisne, ali i oslobođene od tzv. informacionog rizika postiže se pomoću adekvatne računovodstvene regulative, koja je trojaka: zakonska, profesionalna i interna.

Društvena uloga računovodstva u našim uslovima je regulisana Zakonom o računovodstvu i Zakonom o reviziji računovodstvenih iskaza i jugoslovenskim računovodstvenim standardima, računovodstvenim principima i kodeksom profesionalne etike računovođa i revizora, koje je doneo Savez računovođa i revizora kao i opšta načela bilansiranja koja su sadržana i IV Direktive Evropske Zajednice.

\section{Kontrola i sistem internih kontrola}

Sistemi internih kontrola ne štite dovoljno donosioce investicionih odluka, mimo preduzeća, od mogućnosti velikih prevara menažmenta. Međutim, sam sistem internih kontrola služi menadžmentu preduzeća da bude sigurniji da su računovodstvene informacije samog preduzeća pouzdane. (Miljković, 2006) Vrhovni menadžment jednog preduzeća u 
mogućnosti je da „preskoči“ interne kontrole kada dolazi do izveštavanja okoline izvan organizacije. Zaštita koju može da obavi sistem internih kontrola svodi se na to da zahvaljujući razgraničenju dužnosti, u okviru preduzeća i u okviru računovodstva, mnogo ljudi postaje svesno opasnosti od prevare menadžmenta, te mogu da spreče nepošteni menadžment $u$ izbegavanju računovodstvenih politika preduzeća i međunarodnih standarda procenjivanja bilansnih pozicija. (Ranković, 1989)(Van Horne, 1997)

\section{Revizija}

Finansijske revizije su orijentisane na obezbeđivanju donosioca odluka izvan preduzeća uveravanjima da su finansijski izveštaji preduzeća pouzdani. Interne i eksterne finansijske revizije imaju za zadatak da iskontrolišu postojanje i funkcionisanje samog sistema internih kontrola, a isto tako da obezbede uvid i verifikaciju samih finansijskih izveštaja.

Finansijske izveštaje preduzeća sastavlja menadžment preduzeća. Revizija tih izveštaja premošćava jaz poverenja između menadžmenta i korisnika tih izveštaja. Revizori, kako interni tako i eksterni rade u skladu sa načelima i standardima struke. Revizori svoja istraživanja oblikuju tako da pronađu greške koje bi mogle da budu značajne u odnosu na finansijske izveštaje. Njihov rad se sastoji iz prethodnih postupaka, prethodnih postupaka završne revizije i same završne revizije finansijskog izveštaja. Nakon zaključivanja ispitivanja oni izdaju revizorski izveštaj, izražavajući svoje mišljenje o ispravnosti finansijskih izveštaja. Interna revizija je oblik nadzora nad računovodstvenim i administrativnim kontrolama, ali i nešto mnogo više, ona je posebna filozofija dodavanja vrednosti organizaciji svojom aktivnošću. (Moeller\&Witt, 1999)

\section{Revizija u Republici Srbiji}

Problematika regulisanja revizije finansijskih izveštaja sve više zaokuplja pažnju međunarodnih i drugih organizacija. Ona dobija na značaju naročito u uslovima sve šire povezanosti međunarodnih tržišta kapitala i izraženog delovanja multinacionalnih kompanija na globalnom tržištu.

Istinitost i objektivnost, revizijom se utvrđuje $i$ ocenjuje za finansijski položaj, rezultate poslovanja i novčani tok. (Milojević, 2011) Osnova za davanje mišljenja revizora obezbeđuje se ispitivanjem pozicija u računovodstvenim izveštajima. Svi postupci revizije obavljeni radi obezbeđenja dokaza za davanje mišljenja ovlašćenog revizora dokumentuje se, a dokumentacija se čuva posebno za svako pravno lice kod koga se vrši revizija.

Prema Međunarodnim revizorskim standardima, revizor treba da oceni pouzdanost sistema interne kontrole i u kojoj meri može računati da ona obezbeđuje objektivnost računovodstvenih izveštaja. Sistem interne kontrole, prema standardima, obuhvata i specifične kontrolne postupke koje je uvelo pravno lice, kao što su: izveštavanje, pregled $i$ odobravanje izveštaja, kontrolisanje aplikacija i okruženja kompjuterskih informacionih sistema, vođenje i analiza sintetičkih i analitičkih računa i bruto bilansa, odobravanje i kontrolisanje dokumentacije, upoređivanje podataka iz sopstvene evidencije sa podacima iz spoljnih izvora, upoređivanje rezultata popisa sa računovodstvenim evidencijama, upoređivanje i analiza planiranih rezultata sa ostvarenim iznosima itd.

\section{Ocena boniteta preduzeća}

Instituti internih kontrola, operativne revizije $i$ kontrolinga postaju instrument savremenog menadžmenta za upravljanje i rukovođenje, te za permanentnu ocenu boniteta preduzeća.

Zasnovana na finansijskoj analizi, šira ocena boniteta primenjena za svoje unutrašnje potrebe, kao i za potrebe spoljnih korisnika, vezuje menadžment u situaciju da proverava sebe i samoispituje sebe u lancu zavisnosti sa postavljenim ekonomskim parametrima. (Pejić \& dr, 1991)

Finansijska analiza se bavi istraživanjem, kvantificiranjem i analitičkim interpretiranjem funkcionalnih relacija koje postoje između bilansnih pozicija (bilansa stanja i bilansa uspeha), sa ciljem da se omogući validna ocena finansijske pozicije i rentabiliteta poslovanja preduzeća.

Pretpostavka finansijskoj analizi preduzeća, te na njenoj osnovi davana mišljenja o bonitetu preduzeća podrazumevaju i formalno - ispravno generisanje bilansnih podataka i korektno i tačno grupisanje bilansnih pozicija. Ocena nivoa organizovanosti računovodstvene funkcije može, kao faza koja prethodi, da pruži sliku o verodostojnosti podataka koji su predmet analize. (Nićin\&dr, 2011)

Ocenjivanje boniteta preduzeća kao ekonomske kategorije obuhvata ukupnu poziciju preduzeća, utvrđivanje njihove solidnosti ukupne aktivnosti, 
proizvodnih i razvojnih programa, dobru reputaciju u poslovnom svetu, kreditnu sposobnost i likvidnost, što znači i solidnu poziciju na tržištu.

Danas se u koncipiranju teorijsko metodološke osnove ocene boniteta insistira na akceptiranju šireg koncepta poimanja boniteta preduzeća, po kojem ova kompleksna ekonomska i računovodstvena kategorija reprezentuje ukupnu poziciju preduzeća.

Širi koncept definisanja boniteta preduzeća nalaže razmatranje nivoa organizovanosti poslovnih funkcija, odnosno nalaže ocenu nivoa integracije poslovnih funkcija. Ova ocena dobija se metodom ispitivanja funkcija operativnom revizijom. (Nićin\&Paspalj, 2011)

Interes preduzeća se ne može svesti samo na sagledavanje boniteta sopstvene organizovanosti, jer u cilju minimiziranja poslovnog rizika preduzeće treba da sagleda bonitet svojih poslovnih partnera, kako bi kompleksno posmatran bonitet preduzeća dao elemente rizika brojnih faktora iz okruženja zbog uslova privređivanja, ekonomske politike i negativnih dejstava inflatornih kretanja.

Polazna osnova za kreiranje globalne ocene o bonitetu nekog preduzeća jeste analiza nivoa organizovanosti poslovnih funkcija, s obzirom da se aktivnost preduzeća odvija kroz područja poslovnih funkcija.

\section{Operativna revizija}

Operativna revizija je sveobuhvatna delatnost, koja je osmišljena da analizira organizacionu strukturu, sisteme interne kontrole, tok radnog procesa, širu ocenu boniteta i rezultate rada menadžmenta. Operativna revizija je instrument poslovanja preduzeća, alat menadžmenta, ali i njegov korektor. (Dickov \& dr, 2004) Ona meri ostvarenje neke organizacije u odnosu na njenu svrhu i postavljene ciljeve. Operativna revizija se bavi celokupnim ostvarenjem ciljeva, efektivnošću poslovnih postupaka i interne kontrole, rezultatima pojedinih menadžera i drugim finansijskim aspektima poslovanja.
Operativna revizija je tehnika, korišćena od strane preduzeća, ali i organizacije za ocenu preduzeća, kojom se ocenjuje uspešnost preduzeća, efektivnost i priroda poslovnih procesa.

Operativna revizija koristi logičke revizijske tehnike da privede svrsi organizacione ciljeve, operacije, kontrolne procese, komunikaciju i informacioni sistem. (Chambres \& dr, 2000)

Metodologija operativne revizije bazirana na oceni boniteta u širem smislu, usmerena na procese i aktivnosti u preduzeću, daje mogućnost ocene $3 \mathrm{E}$ za pojedine celine i postupke. (Chambers \& Rand, 2004) Operativni revizori moraju razumeti različito značenje efektivnosti, efikasnosti i ekonomije. Efektivnost (raditi prave stvari), meri srazmeru stvarnih rezultata i planiranih rezultata. Efikasnost (raditi dobro prave stvari), meri srazmeru stvarnih unosa i stvarnih rezultata. Ekonomija (raditi jeftino prave stvari), meri srazmeru planiranih unosa $i$ stvarnih rezultata u okviru troškova jedinice.

Proizvodi operativne revizije mogu da variraju od izveštaja koji preporučuje poboljšanje efikasnosti tekućeg poslovanja, do opštih preporuka kako koristiti resurse preduzeća radi najveće dugoročne koristi za preduzeće. Izveštaji mogu da sadrže preporuke za rekonstrukciju sektora, preporuke za zamenu ili obuku kadrova, ili rezultate analize troškova i rezultata kod primene interne kontrole $u$ preduzeću. Operativna revizija podrazumeva proučavanje menadžerskih i administrativnih uspeha poslovanja izabranih aspekata aktivnosti organizacije. Operativna revizija procenjuje uspešnost i bonitet preduzeća, identifikuje potencijalna mesta poboljšanja i daje preporuke za poboljšanje, odnosno dalje akcije.

Operativna revizija razvila se brzo nakon poslednjih 40 godina zbog brzog rasta $\mathrm{i}$ decentralizacije korporativnih organizacija. Koncept operativne revizije je star, no njegova primena na gotovo bezgraničan broj nefinansijskih problematičnih područja $u$ organizaciji pojavila se tek tokom nekoliko poslednjih godina.

\section{Citirani radovi}

Andrić, M. (1999). Revizija računovodstvenih iskaza. Subotica: Ekonomski fakultet.

Chambers, A., Rand G. (2000). The Operational Auditing Handbook. Chichester: John Wiley \& Sons. 
Dickov, V., Nerandžić, B., Perović, V. (2004). Ekonomika moderna,Stilos,Novi Sad Mandić, T. (2001). Komunikologija, Beograd: Grmeč - Privredni pregled.

Milojević, D. (2010). Finansijska kontrola i revizija. Beograd: Beogradska poslovna škola - visoka škola strukovnih studija.

Milojević, D. (2011). Hrestomatija nezavisne revizije, Nauka i društvo, Beograd

Miljković, A. (2006). Finansijska kontrola i revizija. Novi Sad: Privredna akademija.

Moeller, R., Witt, H. (1999). Brinks Modern Internal Auditing, New York: John Wiley \& Sons.

Nićin, N. i dr. (2011). Teorija i analiza bilansa. Beograd: Nauka i društvo.

Nićin, N., Paspalj, M. (2011). Ekonomija. Beograd: Beogradska poslovna škola - visoka škola strukovnih studija.

Pejić, L., Radovanović, R., Stanišić, M. (1991). Ocena boniteta preduzeća. Beograd: Privredni pregled.

Pušara, K. (2004). Međunarodne finansije. Beograd: Univerzitet Braća Karić.

Ranković, J. (1989). Upravljanje finansijama preduzeća. Beograd: Centar.

Van Horne, J. C. (1997). Finansijsko upravljanje i politika. Zagreb: Mate.

Weihrich, H., Koontz, H. (1994). Menadžment, Mc Graw - Hill, Inc., Zagreb: Mate.

Datum prve prijave:

Datum prihvatanja članka:
29.10.2012.

16.11.2012.

\section{Kako citirati ovaj rad?}

Style - APA Sixth Edition:

Nićin, N., \& Bogavac., M. (2013, 01 15). Operativna revizija - alat i korektor menadžmenta. (Z. Čekerevac, Ed.) FBIM Transactions, 1(1), 27-32. Retrieved from www.meste.org/fbim/FBIM 1 2013/ 03.pdf.

doi: 10.12709/fbim.01.01.01.03

Style - Chicago Fifteenth Edition:

Nićin, Nevenka, and Milija Bogavac. "Operativna revizija - alat i korektor menadžmenta." Edited by Zoran Čekerevac. FBIM Transactions (MESTE NVO) 1, no. 1 (01 2013): 27-32.

Style - GOST Name Sort:

Nićin Nevenka and Bogavac. Milija Operativna revizija - alat i korektor menadžmenta [Journal] = Operativna revizija - alat i korektor menadžmenta // FBIM Transactions / ed. Čekerevac Zoran. - Beograd : MESTE NVO, 01 15, 2013. - 1 : Vol. 1. - pp. 27-32.

\section{Style - Harvard Anglia:}

Nićin, N. \& Bogavac., M., 2013. Operativna revizija - alat i korektor menadžmenta. FBIM Transactions, 1501 , $1(1)$, pp. 27-32.

Style - ISO 690 Numerical Reference:

Operativna revizija - alat i korektor menadžmenta. Nićin, Nevenka and Bogavac., Milija. [ed.] Zoran

Čekerevac. 1, Beograd : MESTE NVO, 01 15, 2013, FBIM Transactions, Vol. 1, pp. 27-32. 